\title{
Pengaruh Gaya Pembelajaran dan Kecekapan Murid dalam Penggunaan E-Pembelajaran
}

Influence of Students' Learning Style and Efficiency on the Usage of E-Learning

\author{
Mohd Farid Hassan ${ }^{1}$, Azniah Ismail ${ }^{2}$ \\ ${ }^{1}$ Universiti Pendidikan Sultan Idris; dh4800@gmail.com \\ ${ }^{2}$ Universiti Pendidikan Sultan Idris; azniah@fskik.upsi.edu.my \\ DOI: https://doi.org/10.37134/jictie.vol7.1.7.2020
}

\begin{abstract}
Abstrak
Kajian ini bertujuan untuk mengkaji pengaruh gaya pembelajaran dan kecekapan dalam kalangan murid dalam menggunakan e-pembelajaran di sekolah. Kajian ini berbentuk kaedah tinjauan deskriptif. Bilangan responden untuk kajian ini ialah sebanyak 82 murid tahun lima dari lima buah sekolah yang tepilih dalam kawasan PPD Kubang Pasu, Jitra, Kedah. Instrumen kajian ini menggunakan soal selidik berskala Likert 5 poin dan di analisis menggunakan aplikasi SPSS Versi 21. Dalam kajian ini, penyelidik akan melihat kekuatan hubungan di antara gaya pembelajaran dan kecekapan murid yang mempengaruhi penggunaan e-pembelajaran. Hasil kajian mendapati hubungan gaya pembelajaran murid dengan kecekapan adalah rendah. Begitu juga dengan hubungan bahan pembelajaran dengan kecekapanan murid adalah rendah. Kajian ini diharap dapat menyelesaikan masalah kadar penggunaan e-pembelajaran yang rendah dalam kalangan murid.
\end{abstract}

Kata Kunci: gaya pembelajaran, kecekapan, e-pembelajaran, bahan pembelajaran.

\begin{abstract}
This research aimed to study the influence of learning style and efficiency among students in using elearning at schools. The research used a descriptive survey method. The number of respondents for this study was 82 year-five students from five selected schools in the area of PPD Kubang Pasu, Jitra, Kedah. The instrument used for this research was a questionnaire with a 5-point Likert scale and analysed using SPSS Version 21 application. In this research, researchers will look at the strength of the relationship between students' learning styles and efficiency that influence the usage of e-learning. The study found that the relationship between the students' learning style and effectiveness was low. Similarly, the relationship between learning materials and student's achievement was low. It is hoped that this research will solve the problem in low rate of e-learning usage among students.
\end{abstract}

Keywords: learning style, efficiency, e-learning, learning materials. 


\section{PENGENALAN}

Perkembangan dunia teknologi digital sedang mendapat perhatian yang meluas kerana berpotensi dan mampu memberi perubahan kepada pelbagai bidang termasuklah bidang pendidikan. Bagi memastikan kejayaan penggunaan teknologi dalam bidang pendidikan, Kementerian Pelajaran Malaysia (KPM) telah kerjasama dengan pelbagai syarikat tempatan dengan mengambil inisiatif seperti mengadakan Projek Rintis Sekolah Bestari (bersama Telekom Smart School Sdn. Bhd), projek Frog Virtual Learning Environment atau Frog VLE (bersama 1BestariNet), dan projek Internet 4G tanpa wayar berkelajuan tinggi (bersama YTL Communications). Ia merupakan sebahagian inisiatif Malaysia yang menelan kos belanja yang amat besar (Jabatan Audit Negara, 2014). Walaupun melibatkan kos pelaburan yang besar tetapi projek ini banyak memberi manfaat dan penggunaannya boleh memberi pelbagai kesan positif dalam dunia pendidikan (Nor Azlah \& Fariza, 2014).

Akan tetapi Laporan Ketua Audit Negara (Jabatan Audit Negara, 2014) menyatakan bahawa pelaksanaan pembelajaran maya menggunakan e-pembelajaran di sekolah-sekolah dalam Malaysia adalah kurang daripada 5\% sahaja dan selari dengan hasil kajian Nor Azlah \& Fariza (2014) yang menyatakan bahawa kadar penggunaan e-pembelajaran adalah sangat rendah. Antara isu utama yang dikatakan mempengaruhi keberkesanan pelaksanaan e-pembelajaran adalah seperti kekurangan dari segi fasiliti, sokongan, kesediaan dan beban tugas yang berlebihan (Cheok \& Wong, 2016; Copriady, 2015; Education Quarterly, 2001; Kihoza, Zlotnikova, Bada, \& Kalegele, 2016; Media Asia, 1999; Solar, Sabattin, \& Parada, 2013; Zainon Othman, 2008). Selain itu, terdapat juga kajian yang mengesyorkan guru untuk memberi perhatian terhadap gaya pembelajaran murid (Hasliza Hashim et al, 2016). Ini kerana wujud satu persoalan mengenai bentuk gaya pembelajaran yang disokong oleh sistem e-pembelajaran yang sedia ada.

Sebagai tambahan, jika gaya pembelajaran yang berbeza mempunyai pengaruh yang berlainan terhadap penggunaan e-pembelajaran, maka wujud keperluan untuk mengenalpasti gaya pembelajaran berkenaan agar guru dapat menyediakan bahan pengajaran dan pembelajaran yang bersesuaian dengan keperluan murid. Namun begitu, terdapat juga kemungkinan penggunaan e-pembelajaran mempunyai hubungan dengan faktor kecekapan murid dalam menggunakan e-pembelajaran itu sendiri. Oleh yang demikian, satu kajian diperlukan untuk mengkaji hubungan gaya pembelajaran dan faktor kecekapan yang mempengaruhi penggunaan e-pembelajaran.

\section{OBJEKTIF DAN PERSOALAN KAJIAN}

Matlamat kajian ini adalah untuk mengkaji hubungan di antara gaya pembelajaran, kecekapan dan bahan pembelajaran terhadap penggunaan sistem e-pembelajaran dalam kalangan murid. Jadual 1 menunjukkan objektif dan persoalan kajian bagi mencari penyelesaian masalah penggunaan epembelajaran yang kurang memuaskan. 
Jadual 1: Objektif dan persoalan kajian

\begin{tabular}{ll}
\hline \multicolumn{1}{c}{ Objektif Kajian } & \multicolumn{1}{c}{ Persoalan Kajian } \\
\hline $\begin{array}{l}\text { 1. Mengkaji hubungan antara gaya pembelajaran dengan } \\
\text { kecekapan murid. }\end{array}$ & $\begin{array}{l}\text { Adakah terdapat hubungan antara gaya pembelajaran } \\
\text { dengan kecekapan murid menggunakan e-pembelajaran? }\end{array}$ \\
$\begin{array}{l}\text { 2. Mengkaji hubungan antara bahan e-pembelajaran yang } \\
\text { disesuaikan (mengikut gaya pembelajaran murid) dengan } \\
\text { kecekapan menggunakan e-pembelajaran. }\end{array}$ & $\begin{array}{l}\text { Adakah terdapat hubungan antara bahan e-pembelajaran } \\
\text { yang disesuaikan (mengikut gaya pembelajaran murid) } \\
\text { dengan kecekapan pelajar dalam menggunakan e- } \\
\text { pembelajaran? }\end{array}$ \\
\hline
\end{tabular}

Daripada setiap persoalan kajian tersebut, ada beberapa elemen yang dititikberatkan oleh pengkaji. Bagi persoalan kajian pertama, elemen persoalan kajian yang dikaji ialah hubungan diantara gaya pembelajaran dengan kecekapan dalam kalangan murid dalam menggunakan e-pembelajaran. Manakala bagi persoalan kajian kedua elemen yang dikaji ialah hubungan di antara bahan yang disesuaikan (mengikut gaya pembelajaran murid) dengan kecekapan murid dalam menggunakan epembelajaran samada mengelak atau kurang senang untuk menggunakan e-pembelajaran yang tidak memenuhi gaya pembelajaran mereka dan adakah e-pembelajaran yang memenuhi gaya pembelajaran mereka akan mempengaruhi kecekapan pelajar menggunakan e-pembelajaran. Hasil dari elemen dan kriteria yang dikaji, maka setiap objektif kajian dapat memastikan penggunaan e-pembelajaran VLE Frog yang rendah dapat diatasi sepenuhnya.

\section{KERANGKA KONSEPTUAL}

Kerangka konseptual diadaptasikan dari teori pembelajaran sosial (Bandura, 1977) dan model pemindahan latihan (Baldwin \& Ford, 1988).

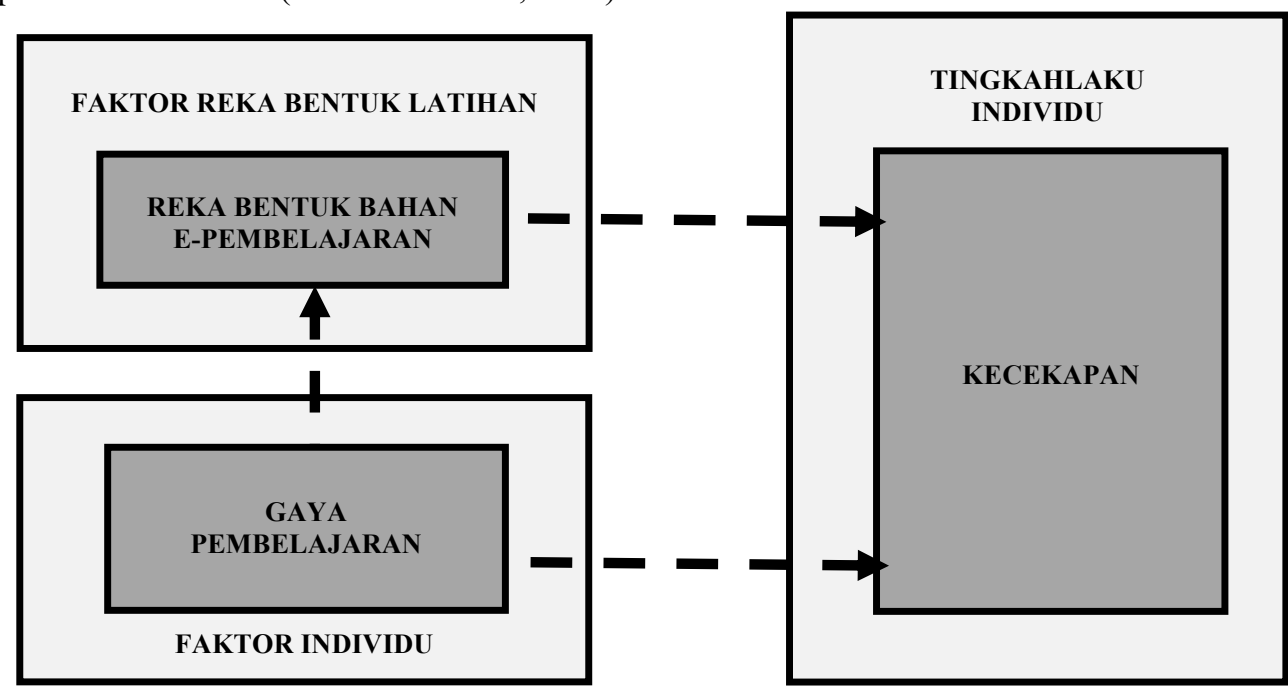

Rajah 1: Model konseptual yang diadaptasi daripada gabungan Model Pemindahan Latihan dan Teori Pembelajaran Sosial 
Dari model konseptual ini menunjukkan beberapa faktor yang mempengaruhi murid menggunakan epembelajaran. Di antara faktornya ialah dari segi gaya pembelajaran dan kecekapan yang mempengaruhi murid untuk menggunakan e-pembelajaran secara berterusan. Daripada model konseptual tersebut, pengkaji memikirkan adakah hubungan diantara gaya pembelajaran murid dengan kecekapan murid akan meningkatkan kadar penggunaan e-pembelajaran dan apakah hubungan bahan e-pembelajaran yang disesuaikan (mengikut gaya pembelajaran murid) dengan kecekapan dalam menggunakan e-pembelajaran. Oleh yang demikian, kajian ini cuba mempertimbangkan sebahagian Teori Pembelajaran Sosial dan Model Pemindahan Latihan dengan mencadangkan kerangka konsep seperti di dalam Rajah 1 bagi melihat hubungan di antara kesemua faktor. Antara faktor-faktor tersebut adalah faktor murid (gaya pembelajaran), faktor bahan P\&P dan faktor kecekapan.

\section{Isu-Isu Kajian}

Nor Azlah \& Fariza (2014) telah menjalankan satu kajian penggunaan e-pembelajaran dalam kalangan murid di seluruh Malaysia. Hasil kajian benar-benar mendapati bahawa kadar penggunaannya pada setiap bulan adalah sangat rendah. Rajah 2 menunjukkan statistik penggunaan e-pembelajaran. Berdasarkan rajah tersebut, didapati bahawa hanya pada bulan Ogos dilihat ada penggunaan dalam kalangan murid.

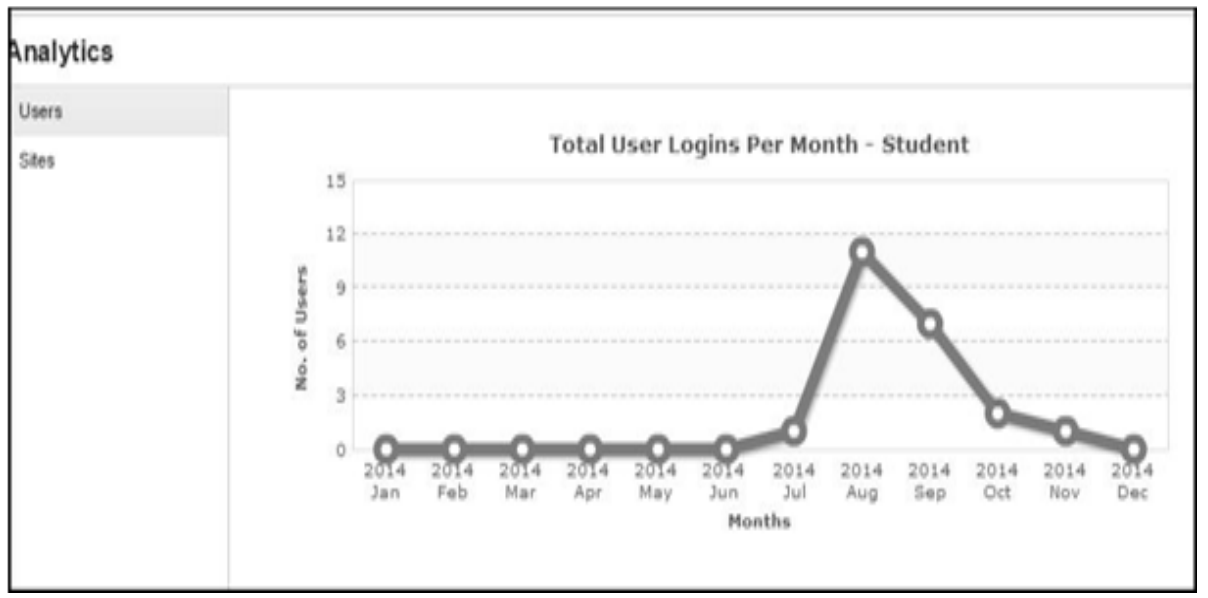

Rajah 2: Statistik penggunaaan e-pembelajaran mengikut bulan (Nor Azlah \& Fariza, 2014)

Antara faktor yang menyebabkan pengunaan e-pembelajaran menjadi rendah ialah kerana faktor individu seperti dapatan kajian (Hammond. et al, 2011; Umar \& Hussin, 2014) menyatakan kurang berkemahiran, keyakinan diri dan pengetahuan untuk menggunakan sesuatu teknologi menjadi penyebab pelajar kurang menggunakan e-pembelajaran. Kajian (Al-Siraihi Al-Harbi, 2011; Badriah \& Ahmad, 2011) menyatakan sifat seseorang individu itu yang mempengaruhi tindak balasnya dalam menggunakan e-pembelajaran. 
Dalam kajian Mohd Nor \& Hazwani (2007), mereka menyatakan bahawa gaya pembelajaran merupakan salah satu faktor yang boleh mempengaruhi keberkesanan pembelajaran murid. Manakala Ena Bhattacharyya \& Ameri (2014), merumuskan bahawa setiap murid mempunyai gaya pembelajaran yang tersendiri, setiap murid lelaki dan perempuan cenderung dalam memilih gaya pembelajaran yang sesuai dengannya.

\section{METODOLOGI}

Reka bentuk yang digunakan dalam kajian ini adalah kaedah tinjauan secara kuantitatif. Dapatan kajian ini dilaporkan secara deskriptif. Instrumen dalam kajian ini menggunakan soal selidik berskala Likert 5 poin yang diadaptasikan dari Reid (1987). Responden kajian ini dipilih secara rawak bertujuan dan terdiri daripada kalangan murid darjah lima yang mempelajari subjek TMK di sekolah rendah dalam PPD Kubang Pasu, Jitra Kedah. Bilangan responden untuk kajian ini adalah seramai 82 orang murid daripada lima buah sekolah yang terpilih. Semua data yang dikumpulkan dianalisis menggunakan Statistical Package for Sosial Science (SPSS) Versi 21. Pendekatan yang digunakan untuk analisis data adalah pendekatan statistik deskriptif di mana data yang diperolehi dibentangkan dalam bentuk jadual dan data dianalisis dari segi kekerapan, peratusan, min, sisihan piawai dan ujian korelasi Pearson.

\section{DAPATAN KAJIAN}

Daripada analisis yang telah dilakukan, nilai pekali kolerasi antara gaya pembelajaran murid dengan kecekapan murid bagi murid jenis gaya pembelajaran audio adalah 0.134 . Manakala bagi murid yang gaya pembelajaran jenis visual pula, nilai pekali kolerasi untuk gaya pembelajaran visual dengan kecekapan ialah -0.012. Hasil analisis mendapati gaya pembelajaran dan kecekapan dalam menggunakan komputer bagi setiap pelajar tidak mempengaruhi pelajar dalam menggunakan epembelajaran.

Bagi kajian untuk menentukan hubungan antara bahan pembelajaran (bahan yang bersesuaian dengan gaya pembelajaran murid) dengan kecekapan murid menggunakan komputer menunjukkan nilai pekali kolerasi antara gaya pembelajaran murid dengan kecekapan murid adalah berbeza. Hasil analisis menunjukkan nilai pekali kolerasi bagi hubungan gaya pembelajaran audio yang disesuaikan bahan pembelajaran dengan kecekapan mengunakan komputer ialah 0.134 . Manakala nilai pekali kolerasi untuk hubungan gaya pembelajaran visual yang disesuaikan bahan pembelajaran dengan kecekapan menggunakan komputer ialah 0.162. Analisis ini mendapati bahan pembelajaran murid (bahan pembelajaran yang telah disesuaikan dengan gaya pembelajaran murid) tidak mempengaruhi kecekapan dalam menggunakan komputer bagi murid audio ataupun visual. Ini kerana nilai pekali korelasi dalam lingkungan 0.00 hingga 0.29 dan dianggap lemah.

Manakala bagi hubungan bahan pembelajaran (bahan yang tidak disesuaikan dengan gaya pembelajaran murid) dengan kecekapan murid menggunakan komputer yang dilakukan menunjukkan nilai pekali kolerasi untuk bahan pembelajaran visual (murid gaya pembelajaran audio) dengan 
kecekapan menggunakan komputer pelajar audio ialah 0.087. Manakala nilai pekali kolerasi bagi hubungan bahan pembelajaran audio (murid gaya pembelajaran visual) dengan gaya kecekapan menggunakan komputer pelajar visual ialah 0.158. Daripada hasil analisis ini mendapati nilai pekali kolerasi bagi bahan pembelajaran (bahan yang tidak disesuaikan dengan gaya pembelajaran murid) dengan kecekapan menggunakan komputer adalah rendah. Ini kerana nilai pekali korelasi berada dalam lingkungan 0.00 hingga 0.29 dan menunjukkan anggaran kekuatan perhubungan antara dua pembolehubah itu lemah.

\section{KESIMPULAN}

Kajian ini berfokus kepada menyelesaikan masalah penggunaan e-pembelajaran yang rendah. Dalam kajian ini, pengkaji cuba merungkai secara lebih mendalam apakah faktor-faktor berkaitan yang dirasakan mempunyai pengaruhi keberkesanan e-pembelajaran sama ada secara langsung atau tidak langsung. Antara faktor yang dikaji ialah faktor gaya pembelajaran, kecekapan penggunaan dan juga bahan pengajaran yang sesuai dengan gaya pembelajaran. Hasil kajian ini diharap akan memberi impak dan cadangan penyelesaian yang baik terhadap isu keberkesanan pelaksanaan e-pembelajaran dan seterusnya membantu mencapai matlamat Kementerian Pendidikan Malaysia yang mahu menjadikan Malaysia sebagai satu hab pendidikan yang terbaik di dunia.

\section{RUJUKAN}

Al-Siraihi Al-Harbi, K. (2011). E-Learning in the Saudi tertiary education: Potential and challenges. Applied Computing and Informatics, 9, 31-46.

Badariah, T. \& Ahmad, T. (2011). Between School Factors and Teacher Factors: What Inhibits Malaysian Science Teachers From Using ICT? The Malaysian Online Journal of Educational Technology, 2(1), 1-10.

Baldwin, T. T., \& Ford, K. J. (1988). Transfer of training: A review and directions for future research. Personnel Psychology, 41(1), 63-105.

Bandura, A. (1977). Toward a unifying theory of behavioral change. Psychologist, 37, 122-147.

Cheok, M. L., \& Wong, S. L. (2016). Frog Virtual Learning Environment for Malaysian Schools: Exploring Teachers' Experience. In J. Zhang et al. (Ed.), ICT in Education in Global Context (201-209). Singapore: Springer Science+Business Media. https://doi.org/10.1007/978-3-662-43927-2

Copriady, J. (2015). Self-Motivation as a Mediator for Teachers' Readiness in Applying ICT in Teaching and Learning. Procedia - Social and Behavioral Sciences, 176, 699-708. https://doi.org/10.1016/j.sbspro.2015.01.529

Education Quarterly (2001). Managing Knowledge. 16 (May/June), 34-35.

Ena Bhattacharyya \& Ameri Bin Mohd Sarip @ Shariff (2014). Learning Style and Its Impact in Higher Education and Human Capital Needs, Procedia Social and Behavioral Sciences, 123,485 - 494

Hammond, M., Reynolds, L. \& Ingram, J. (2011). How and why do student teachers use ICT? Journal of Computer Assisted Learning, 27(3), 191-203.

Hasliza Hashim, Siti Munira Mohd Nasri, \& Zarina Mustafa. (2016). Cabaran yang dihadapi oleh guru dalam pelaksanaan persekitaran pembelajaran maya frog di bilik darjah. Asia Pacific Journal of Educators and Education, 31, 115-129. http://dx.doi.org/10.21315/apjee2016.31.7

Jabatan Audit Negara. (2014). Laporan Ketua Audit Negara bagi Tahun 2013: Siri 3. Jabatan Audit Negara: Malaysia.

Kihoza, P., Zlotnikova, I., Bada, J., \& Kalegele, K. (2016). Classroom ICT Integration in Tanzania: Opportunities and Challenges from the Perspectives of TPACK and SAMR Models. International Journal of Education and Development Using Information and Communication Technology (IJEDICT), 12(1).

Mohd Nor \& Hazwani (2007), Gaya Pembelajaran di Kalangan Pelajar-Pelajar Sarjana Muda Pendidikan Teknik dan Vokasional di Universiti Tun Hussein Onn. Seminar Penyelidikan Pendidikan Institut Perguruan Batu Lintang Tahun 2007. Pembudayaan Penyelidikan Ke Arah Kecemerlangan Profesionalisme Keguruan.

Nor Azlah Mohd Jaafar \& Fariza Khalid (2014). Keberkesanan kemahiran komunikasi di kalangan guru dalam penggunaan persekitaran pembelajaran maya (Frog VLE). Fariza Khalid, Md Yusoff Daud \& Mohd Jasmy Abd Rahman (Eds.). Aliran 
Pengaruh Gaya Pembelajaran dan Kecekapan Murid dalam Penggunaan E-Pembelajaran

Received Date: 01 February 2020; Accepted Date: 01 June 2020

Terkini Dalam Pengajaran Sumber \& Teknologi Maklumat: Impaknya ke atas Penyelidikan dalam Pendidikan, 64-68. Bangi: Penerbit Fakulti Pendidikan, UKM.

Reid, M. J. 1987. The learning style preferences of ESL students. TESOL Quarterly.

Solar, M., Sabattin, J., \& Parada, V. (2013). A Maturity Model for Assessing the Use of ICT in School Education. Educational Technology \& Society, 16(1), 206-218.

Umar, I. \& Hussin, F. (2014). ICT Coordinators' Perceptions on ICT Practices, Barriers and its Future in Malaysian Secondary Schools: Correlation Analysis. Procedia - Social and Behavioral Sciences, 116, 2469-2473.

Zainon Othman. (2008). Penyelidikan mengenai e-Pembelajaran: Satu kes kolej sains dan teknologi. Mohd Fuad Mohd Salleh (Ed.). Isu-Isu Pembelajaran E Dalam Pengajian Tinggi Malaysia, 113-127. Univision Press: Universiti Teknologi Malaysia. 